Article

\title{
Experiences with Citizen-Sourced VGI in Challenging Circumstances
}

\author{
Mustafa Hameed ${ }^{1, *}$, David Fairbairn ${ }^{1}$ and Suzanne Speak ${ }^{2}$ \\ 1 School of Engineering, Newcastle University, Newcastle NE1 7RU, UK; david.fairbairn@newcastle.ac.uk \\ 2 School of Architecture, Planning and Landscape, Newcastle University, Newcastle NE1 7RU, UK; \\ s.e.speak@newcastle.ac.uk \\ * Correspondence: m.r.hameed@newcastle.ac.uk; Tel.: +44-75-7042-1032
}

Received: 20 October 2017; Accepted: 22 November 2017; Published: 26 November 2017

\begin{abstract}
The article explores the process of Volunteered Geographic Information (VGI) collection by assessing the relative usability and accuracy of a range of different methods (smartphone GPS, tablet, and analogue maps) for data collection among different demographic and educational groups, and in different geographical contexts within a study area. Assessments are made of positional accuracy, completeness, and the experiences of citizen data collectors with reference to the official cadastral data and the land administration system. Ownership data were validated by crowd agreement. The outcomes of this research show the varying effects of volunteers, data collection method, geographical area, and application field, on geospatial data handling in the VGI arena. An overview of the many issues affecting the development and implementation of VGI projects is included. These are focused on the specific example of VGI data handling presented here: a case study area where instability and lack of resources are found alongside strong communities and a pressing need for more robust and effective official structures. The chosen example relates to the administration of land in an area of Iraq.
\end{abstract}

Keywords: volunteer geographic information; positional accuracy; land administration systems

\section{Introduction}

The term 'Volunteer Geographic Information' (VGI) was introduced by Goodchild [1], to describe the widespread participation of the private citizen in creating geographic information, a function that, for centuries, had been reserved to official agencies [2]. The majority of VGI projects have concentrated on building web applications that allow citizens, using the Internet and contemporary technology, to access and edit or create features with reference to maps, satellite images, and ground-based methods. However, such projects may not always be successful in developing countries, such as Iraq, where Internet connections may not be good, the majority of citizens have no knowledge of using web map applications, and there are problems in engaging with communities, especially in rural areas [3].

Only $25 \%$ of nations (mostly industrial countries, 35-50 in total) have a complete land registration system: lack of finance, limited institutional capacity, and ineffective political will, mean that $75 \%$ of the world's land parcels have not yet been registered. The majority of their occupants are the most vulnerable and poorest groups in society, and they live under threat of expulsion due to lack of security of tenure [4]. Clearly, improved systems and practices are required, and it is suggested that cooperation with the local community could accelerate the creation of land administration systems which are appropriate, realistic, sustainable, manageable, and effective, i.e., fit-for-purpose.

The priority of a 'fit-for-purpose' system is not necessarily high spatial accuracy, but rather the effective recording of ownership and provision of security of tenure for underprivileged communities [5]. Building such a system could incorporate efforts of local citizens, with different levels of education and background, and utilizing varying technologies. The majority of previous research 
in VGI concentrated on the general drive, nature, and applications of the crowdsourced data, i.e., data collated from contributions of a number (often with redundancy) of 'amateurs', non-officials, or volunteers. It mainly focused on the nature of projects such as OpenStreetMap (OSM) and Wikimapia, but with little research on the fitness for use of VGI in official domains, such as land administration. Keenja et al. [6] reported that "to date, limited empirical work has been undertaken in this domain: there remain many unanswered questions regarding the accuracy, authority, assuredness, availability, and ambiguity of crowdsourced data. Meanwhile, the potential for crowdsourcing to provide a low cost and high-speed solution in areas where cadastral coverage is lacking, is eagerly anticipated". Basiouka, Potsiou, and Bakogiannis [7] used volunteers to assess the possibility of using OSM for official, cadastral purposes, but the target group was college-educated surveying practitioners, rather than real members of the community. Other researchers, such as Grus and Hogerwerf [8], have reported on experiences of crowdsourcing in the Netherlands' Kadaster, concentrating on change detection, whilst de Almeida et al. [9] explored the role of VGI in capturing and utilizing 3D data for property cadastres.

The study presented here examines VGI data collection, involving a wide range of community citizens, and several digital and analogue collection methods acceptable to them, to investigate contributions to official land administration systems (LAS). The paper is based on research and fieldwork in Iraq undertaken in 2016. The next section covers the issues which affect the role of VGI in land administration projects. Section 3 introduces the research project undertaken in Iraq, and its results are reported in Section 4. Following discussion, it is suggested that, in areas of conflict or when official systems are under extreme stress, VGI may be the only realistic method of collecting usable data.

\section{Contextual Issues in VGI for Land Administration}

There are many issues which influence and directly affect the operation of VGI projects for the purposes of land management. Land administration is a crucial governmental function, and its effective delivery in a dysfunctional environment, such as modern-day Iraq, is difficult. The concept of public participation in such activity can be problematic for both authorities and citizens. Further, the nature and quality of data collected by volunteer citizens must be addressed. It may also be possible to learn from other investigations into the potential of VGI, and into the governance and methods of land administration. The most significant issues for the case study presented here are outlined in this section.

\subsection{Approaches to the Public Participatory Collection of Geographic Data}

Mass contributions of VGI are referred to as 'crowdsourcing' [10], generally taking advantage of contemporary mobile devices and the 'geo-web'. The terms 'collaborative mapping' and 'participatory GIS' can be used to describe the application of VGI to land administration; further VGI use is directed towards the concept of 'citizen science' [11]. In the handling of data related to land administration, the subject of the study outlined here, de Vries, Bennett, and Zevenbergen [12] refer to 'neo-cadastres', meaning land-based records built and maintained by citizens. Seeger [13] considers three specific aspects important to the use of VGI in cadastre- and land-based projects: the motivation for volunteer engagement with land administration, the quality of the data, and methods of validation and verification. The case study described here exposed an uncertain group of volunteers to concepts of participatory geographic data collection and its subsequent handling and processing.

\subsection{Citizens' Motivation}

A range of issues may affect or direct the work of a volunteer who collects and handles VGI [14]. Some citizens speak of altruism, professional and personal interest, intellectual stimulation, protection of possible personal investment in the locality, social reward, personal reputation, self-expression, opportunity, and 'pride of place', including improvement in public services [15], as positive reasons 
for their engagement in VGI collection and management. Basiouka and Potsiou [16] suggest that the main motivation for public volunteering might be to overcome bureaucracy and assist in opening land up to more development. More negative factors can also act as drivers, including the promotion of mischief, support of a contrary social, economic, or political agenda, or malice intent (similar to hacking or seeking criminal access to data). Participation can often be seen as recreational, with Cotfas and Diosteanu [17] suggesting that the public does not even need to be particularly aware or motivated for their participation. However, Tulloch [18] suggests that communities and individuals which engage in VGI achieve a higher level of 'empowerment', and this certainly did become a public motivation in this study.

\subsection{VGI as a Contributor to Official Activity}

Haklay et al. [19] present direct uses of VGI in governmental activities. Although some of these are not directly related to cadastral systems, they inform this project with experiences and difficulties that may face the application of VGI to such tasks. In Kibera, Nairobi's biggest informal settlement, VGI was used to create a basic topographic map, enhancing the surveying activities of the national mapping agency [20]. In a more integrated fashion, the Canadian government has developed a project for correcting and updating topographic maps using VGI [21]. VGI can also be used for improving public services, although there is evidence of resistance to its adoption as a regular information source for some local government tasks [22].

Official governmental activity, local, regional, national, and international, typically involves significant amounts of spatial data handling, but it is also characterized by shortcomings in resources which can lessen effectiveness, or may even dissuade communities from engaging with the economic, political, and social management of society. The advantages and experiences of VGI should be communicated to formal structures, including those engaged in administration of a major societal resource, land, and this was a major goal of this study.

\subsection{Accuracy and Completeness Considerations for VGI}

Since VGI is provided, in many cases, by people with little or no knowledge of the mapping process [23], it is necessary to verify the quality of this data and the potential benefits. Further, there is possible divergence between the quality of original cadastral map production and the accuracy of volunteer information, which indicates the need for verification of the latter. The quality of data can comprise several factors [24,25]:

- Positional accuracy is the 'nearness' of coordinate values of a VGI feature (e.g., a captured point) to a corresponding authoritative equivalent feature.

- Thematic or attribute accuracy refers to the reliable and reasonable correctness of semantic information attached to the point, line, and polygon features of the spatial database.

- Completeness refers to the comparison between different datasets for the same area of interest to find which features are included or excluded from a dataset.

- Temporal accuracy refers to the agreement between encoded and 'actual' temporal coordinates [26].

- Logical consistency refers to the identification and resolution of contradictions, relationships, and connections within a dataset [27].

The evaluation of the positional accuracy of VGI can utilize traditional statistical methods, such as root mean square error (RMSE) to describe the spatial error of point features. Fairbairn and Al Bakri [28] reviewed the spatial correspondence between VGI and official government data, finding that the RMSE for OpenStreetMap data against official topographic mapping data was consistently higher than established tolerances, with errors attributed to the low-precision devices, for example, personal GPS units and commercial imagery services, commonly used in VGI data collection. Such measures can vary within a dataset which covers different areas: Zielstra and Zipf [29] found that the quality of VGI became worse the further away it was collected from the urban core. 
Completeness can be assessed by considering the difference between what is recorded (e.g., in the context of a VGI project such as OSM, number of houses or length of roads) and what is actually found in the real-world [30]. Haklay [31] suggested that it is possible to rely on such a numerical assessment, by simply comparing the total length of streets in OpenStreetMap (OSM) with Ordnance Survey (OS) data. Jackson et al. [32], undertook a study counting numbers of identified schools in an area and showing correspondence across four datasets. However, when they repeated the study basing it on specific attributes-e.g., names, addresses-they noted that, although the numbers were similar, the schools themselves were often not identifiably the same. Summarizing completeness based on quantities alone was insufficient to assess this factor.

\subsection{Land Administration Systems in Developing Countries}

Adlington and Tonchovska [33] argue that one of the main reasons for inefficiency of official land administration systems is a lack of funds. Characteristic of many changing economies in less developed countries, public projects in revising, updating or maintaining any official system may fail due to political change and economic transition from central to free markets: $49 \%$ of World Bank supported projects suffer from budget deficiency, exemplified by a study of land administration by Basiouka and Potsiou [16] in Bulgaria. McLaren [4] noted that lack of trained staff also makes official systems inefficient, with Enemark et al. [5] citing Rwanda as an example of this situation.

In practice, governmental systems can be inaccessible for most of the people, especially in developing countries. The lengthy and costly procedures in handling land data mean that poorer people may not register their ownership, and may buy or sell their land without reference to the formal system. Official systems usually record only legally registered land, leaving millions of people whose tenures are predominantly social, rather than legal, as unprotected occupiers [34]. A further issue is the difficulty faced by official systems after change of governmental regime, or following civilian or military conflict [35]. Even where usable systems exist, Al-Bakri and Fairbairn [36] noted shortcomings in completeness and currency as authorities struggle to record increasing numbers of plots and subdivisions, and changes of use. Supplementary or alternative collection, recording, and management procedures, including VGI-based techniques, can appear attractive.

\subsection{Fit-For-Purpose Land Administration}

Where the official cadastral system is weak or does not exist at all, 'fit-for-purpose' systems [5] can be considered. Their main aim is to provide security of tenure for underprivileged communities, using several key principles: general boundaries are used rather than fixed/monumented boundaries, meaning that the accuracy of the delineation process is not necessarily high, especially in rural and peri-urban areas where land values may be low; the use of cheaper satellite or aerial imagery as base mapping is promoted as suitable for land administration; the approach is participatory and inclusive, covering all tenure types, including both legal and de facto occupied; and the resultant system flexibility allows for easy data update and system upgrade. 'Fit-For-Purpose' approaches have been tested in this research study.

\subsection{Evaluating the Use of VGI in the Land Administration System}

De Vries, Bennett, and Zevenbergen [12] argue that the use of VGI in cadastral systems is faster, cheaper, and more fit-for-purpose than the traditional method of official survey and registration. VGI can also act as an interim cadastral solution for securing land rights with different levels of tenure security. However, along with Lanier [37] and Keen [38], they do acknowledge possible conflict between VGI methods and data, and the procedures of official organizations and experts.

Goodchild and Li [39] have concerns about the quality of VGI and the fact that only a small number of people can validate it. In land administration, similar concerns have been expressed by Navratil and Frank [40] who argued that it would be difficult to depend on VGI alone as an alternative for an official cadastral system. The testing of VGI validity, and assessment of conflicts between it and 
official records, are important in determining in its worth. Methods of verifying VGI may include the matching of data against ground truth or accepted values, quality control of the data flowline, the acquired reputation of the volunteer (both as a source of original data and as a checker of others' [41]), or confirmation by multiple data collection methods or individuals [42,43].

\subsection{An Example from Iraq}

In Iraq, the official land administration system has faced many problems since the US-led Occupation in 2003. Large-scale forgery of title deed documents dates from that period. The dysfunctional nature of official systems has led to the seizure of public buildings by people occupying them as their living space, with others illegally squatting on public land and building their own houses on it, bypassing the formal land registration system. Internal migration and displacement of large groups of the Iraqi population have exacerbated property ownership uncertainty and occupation disputes, and rebel political and military groups have established alternative governance in many areas. Current political and economic circumstances do not signify any improved situation, and the sub-optimal nature of the current land administration system in Iraq suggests that an alternative method based on informal data sources is the better approach to improvement.

Each of the contextual aspects presented here in Section 2 has been incorporated into this research, and several are explored in depth later. This wide-ranging set of issues has an effect on the investigation of possible impact of VGI, derived in difficult situations, on dysfunctional organisations charged with official geospatial data handling.

\section{Establishing a VGI Project}

A project was set up to test the applicability and value of VGI in enhancing the land administration system in a province in central Iraq, and the practical procedures employed to handle the VGI. The issues presented in Section 2 were major drivers in establishing a methodology for this project. The governorate of Babil was chosen, and field work was conducted in the region of its capital city, Al-Hillah, $100 \mathrm{~km}$ due south of Baghdad. Here, three types of locality—rural, peri-urban, and urban-were identified. For each type, several specific locations were chosen and the local communities were contacted through gatekeepers identified in collaboration with the local land administration office. The locations varied not only in topography, but in land utilization dynamics, demographic profile, and socio-cultural community. In addition, the coverage of formal land records and maps obtained from the official LAS professionals was different for each site. The variability in methodology extended to the testing of differing data collection methods in each of these areas.

\subsection{Community Sampling}

VGI data collection was undertaken in nine communities: four urban, three peri-urban, and two rural. Preparation involved ensuring engagement with those local leaders who were positive about the research program, and were able to introduce the project to residents. A total of 10-15 volunteer citizens per community were recruited, varying in gender, age, and educational level (Table 1). In a formal workshop environment, volunteers were given full training in the project requirements, in terms of security, anonymity in data handling and instrumentation, and procedures for data collection. Volunteers could choose which technology to use to gather the data. In addition, the implications of giving consent to participation were explained, and a brief overview of the formal land administration procedures was given. Training was delivered, with detailed instructions on both low- and high-tech methods, and on specific issues, such as identifying a plot's 'center point' and being precise in attribute recording. 
Table 1. Characteristics of volunteers who mapped case study areas.

\begin{tabular}{ccccccccc}
\hline & \multicolumn{2}{c}{ Gender } & \multicolumn{3}{c}{ Age } & \multicolumn{3}{c}{ Education level } \\
\hline & Male & Female & $<\mathbf{3 0}$ & $\mathbf{3 0 - 5 0}$ & $>\mathbf{5 0}$ & Uneducated & School & University \\
\hline Urban Communities & 23 & 18 & 15 & 19 & 7 & 6 & 18 & 17 \\
(Four sample areas) & $(56 \%)$ & $(44 \%)$ & $(37 \%)$ & $(46 \%)$ & $(17 \%)$ & $(15 \%)$ & $(44 \%)$ & $(41 \%)$ \\
\hline $\begin{array}{c}\text { Peri-urban Communities } \\
\text { (Three sample areas) }\end{array}$ & $(78 \%)$ & $(22 \%)$ & $(30 \%)$ & $(38 \%)$ & $(32 \%)$ & $(27 \%)$ & $(46 \%)$ & $(27 \%)$ \\
\hline Rural Communities & 27 & 0 & 4 & 10 & 13 & 14 & 9 & 4 \\
(Two sample areas) & $(100 \%)$ & $(0 \%)$ & $(15 \%)$ & $(37 \%)$ & $(48 \%)$ & $(52 \%)$ & $(33 \%)$ & $(15 \%)$ \\
\hline
\end{tabular}

\subsection{VGI Collection}

The methods of data collection are central to the testing of geometric and semantic/attribute data, as well as considering the varying nature of the environment visited, and the personal abilities of the individual volunteers. Three methods were developed and used: (i) smartphone with a GPS app uploaded for locating land parcel corners and attributing the resultant polygon; (ii) portable iPad tablet PCs with the official cadastral map uploaded, and overwriting and annotating capability provided through QGIS; and (iii) paper-printed aerial or satellite image, with clipboard and pencil for demarcation and annotation.

Initial training, interviews, and practical data collection took place with reference to the land parcel presently occupied by the volunteer, to establish familiarity with the method chosen-gathering GPS coordinates of plot boundaries, identifying parcels and annotating maps on a portable tablet, or demarcating and tracing plots on paper images of satellite scenes (Figure 1). It was recognised that scale is an important issue in VGI data collection [44]: for urban and peri-urban areas, tablet mapping and satellite imagery should render the base map data at a large scale (e.g., 1:1500), although smaller scales may be appropriate for rural areas.

Each volunteer surveyed a number of land parcels.

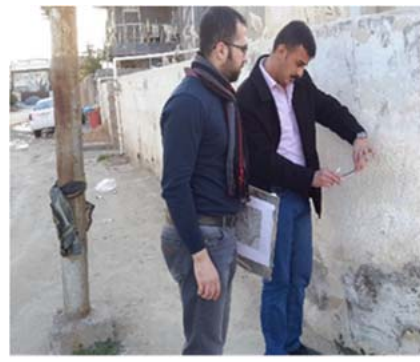

(i)

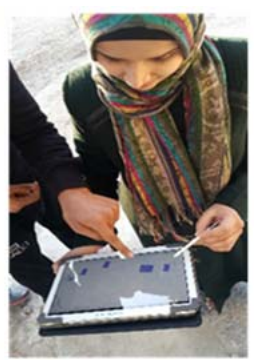

(ii)

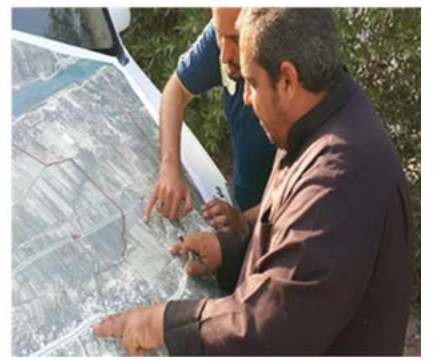

(iii)

Figure 1. Data collection methods applied in different geographical contexts: (i) smartphone GPS in an urban centre; (ii) tablet computer in an urban centre; and (iii) paper aerial image in a rural area.

\subsection{Practical Fieldwork}

The volunteer groups themselves demarcated their precise data collection site (community extent) using standard paper mapping or imagery. The size of such sites was set at $250 \mathrm{~m} \times 250 \mathrm{~m}$ in rural areas (maximum 100 agricultural plots), $150 \mathrm{~m} \times 150 \mathrm{~m}$ in peri-urban zones (maximum 100 land parcels), and $150 \mathrm{~m} \times 150 \mathrm{~m}$ in central urban districts (maximum six city blocks, perhaps including high-rise buildings). Each site was divided to identify specific sub zones for each volunteer to capture the land parcels' geometry. In addition, attribute data for each land parcel (e.g., owner; type of tenure; date of last transaction; land use; date of last land use change (e.g., agriculture to residential)) was captured across the whole site in duplicate by all volunteers. Multiple capture of such attribute data is necessary to provide validation data. The geometric and positional data captured by VGI 
could be tested against reference surveys, existing mapping or imagery, but the attribute data were validated by such crowdsourcing because: (a) official records of ownership are confidential and inaccessible; (b) subdivision has complicated ownership; and (c) contemporary information is required. Further attribute data reflecting environmental change was also recorded by the volunteers-change of river course, building demolition or construction, notification of heritage status, or change in land use. Such information allowed for tests of completeness and currency to be undertaken later, and comparisons made between the official records and the VGI.

\section{VGI Activities and Outputs in Al-Hillah}

A series of field data collection activities were undertaken in each case study area (Figure 2): communities were consulted, citizen volunteers identified, officials interviewed, data collected, and existing official mapping and records were collated. Much of the assessment of VGI methods and outputs involved comparisons with these official datasets. The land administration agency in Al-Hillah retains official records in both textual and in map form. Unfortunately, there are very few records which offer up-to-date information, the vast majority of maps having been produced before 2003 and typically hand-drawn on paper. These show parcel boundaries but little other topographic detail, generally limited to drainage and highways. The scale of such maps is typically 1:1000 for urban areas, 1:2500 for rural areas, and the name of the surveyor and date of survey is shown. One of the nine areas chosen had mapping produced in 1951, with others dating from the 1970s. Such documents are accurate in terms of survey, although the attribute information (e.g., owner's name, land use, etc.) can be vastly out-of-date, and some environments have also changed significantly: for example, in one rural area a new irrigation scheme has radically transformed the layout, and quantity, of land parcels. Unfortunately, most of the maps have no visible coordinate reference system or grid associated with them, but the availability of accurate and contemporary aerial orthophotos has allowed for georeferencing of the maps to take place, and for comparisons to be made between coordinates collected by volunteers on the ground and the records held on official mapping.

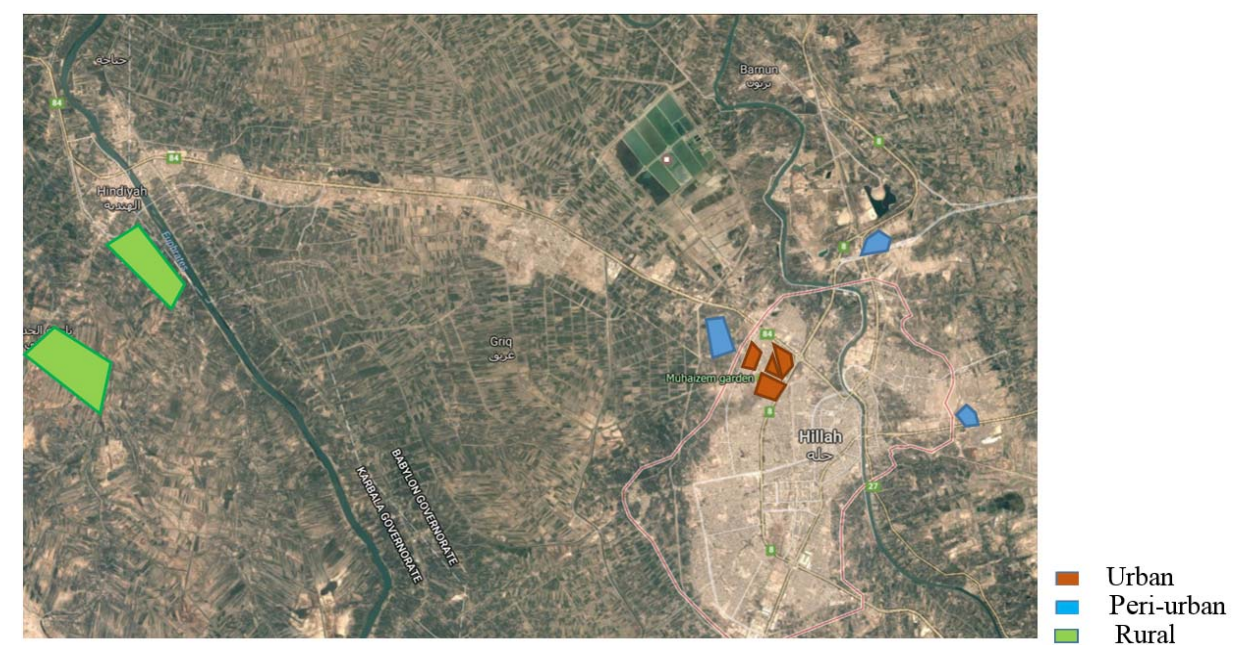

Figure 2. Study site locations, Al-Hillah, Iraq (Google Maps, 2016).

In urban areas, information about the coordinate system and an overlaid grid appear on some maps; but in peri-urban and rural areas all the maps needed to be spatially matched with georeferenced aerial orthophotos, using well-chosen reference points on the imagery.

\subsection{Positional Accuracy Results from VGI}

Significant outputs from this project include the testing of VGI datasets against the official records. Such accuracy testing is done by matching land parcel corners and boundaries from the VGI with the 
formal LAS documentation, which may be a map or a list of coordinates. Each of the three technologies was used to capture a dataset of land parcel corners in each of the nine areas (although the rural areas only used two technologies-smartphone GPS and analogue paper photo). Therefore, a significant number of points captured by each volunteer using all technologies was made available and accuracy comparisons could be calculated (examples of land parcel measurement for an urban and a rural area are shown in Figures 3 and 4). Positional accuracies for datasets created using each data collection method were calculated for each of the nine sites. This involved a RMSE analysis of coordinated corner points of land parcels, assessing the discrepancy between the positions captured using the three methods utilized and the coordinates of those points as shown in the official map records. A customized dashboard tool, developed in MATLAB for calculating and visualizing the RMSE and other measures [28], was used to quantify the discrepancies between VGI and official data (Figure 5).

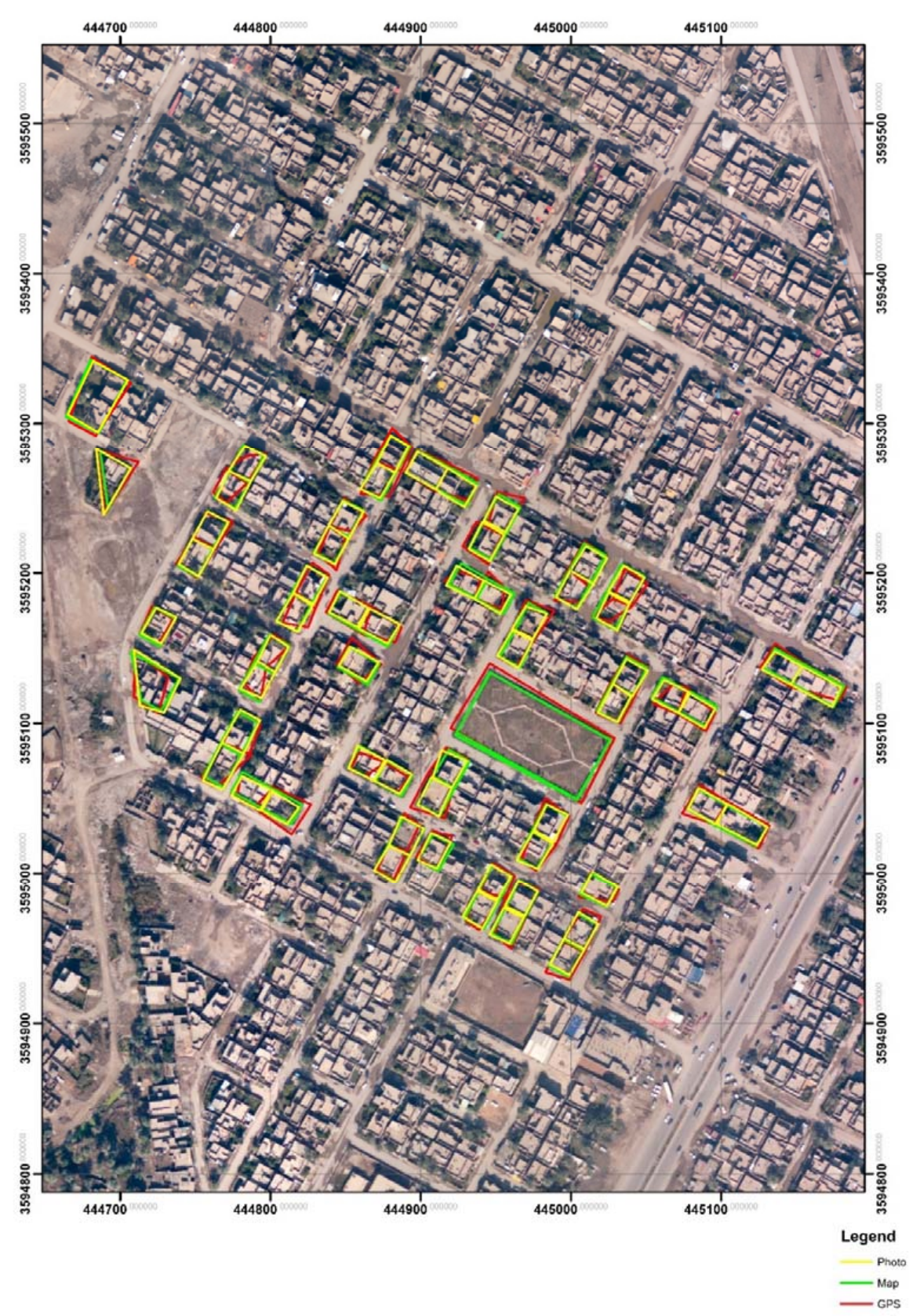

Figure 3. Moharbeen urban area, Al-Hillah. VGI-defined land parcel boundaries using three methods of delineation. 


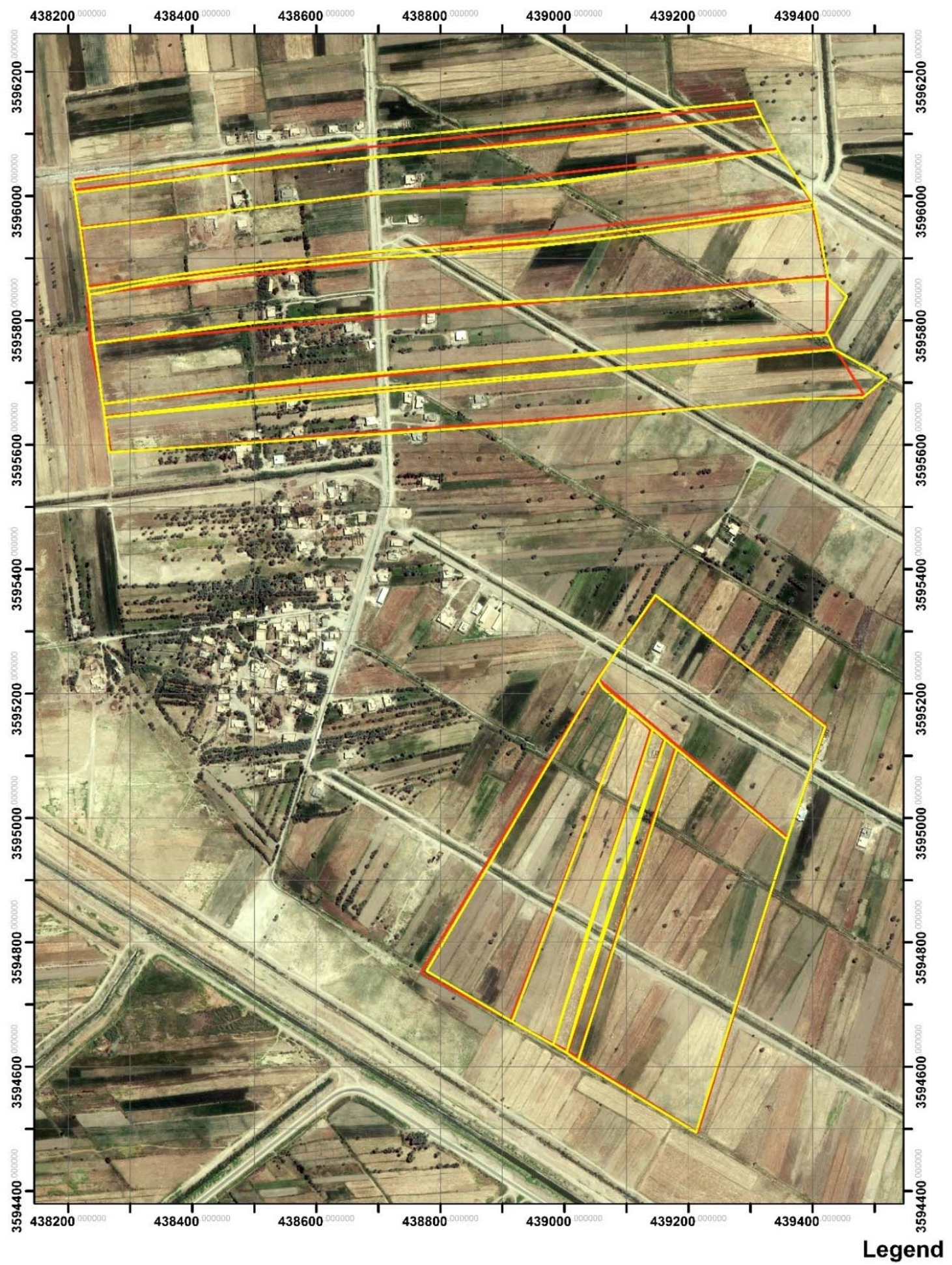

Photo

GPS

Figure 4. Aries rural area, near Al-Hillah. VGI-defined land parcel boundaries using two methods of delineation. 


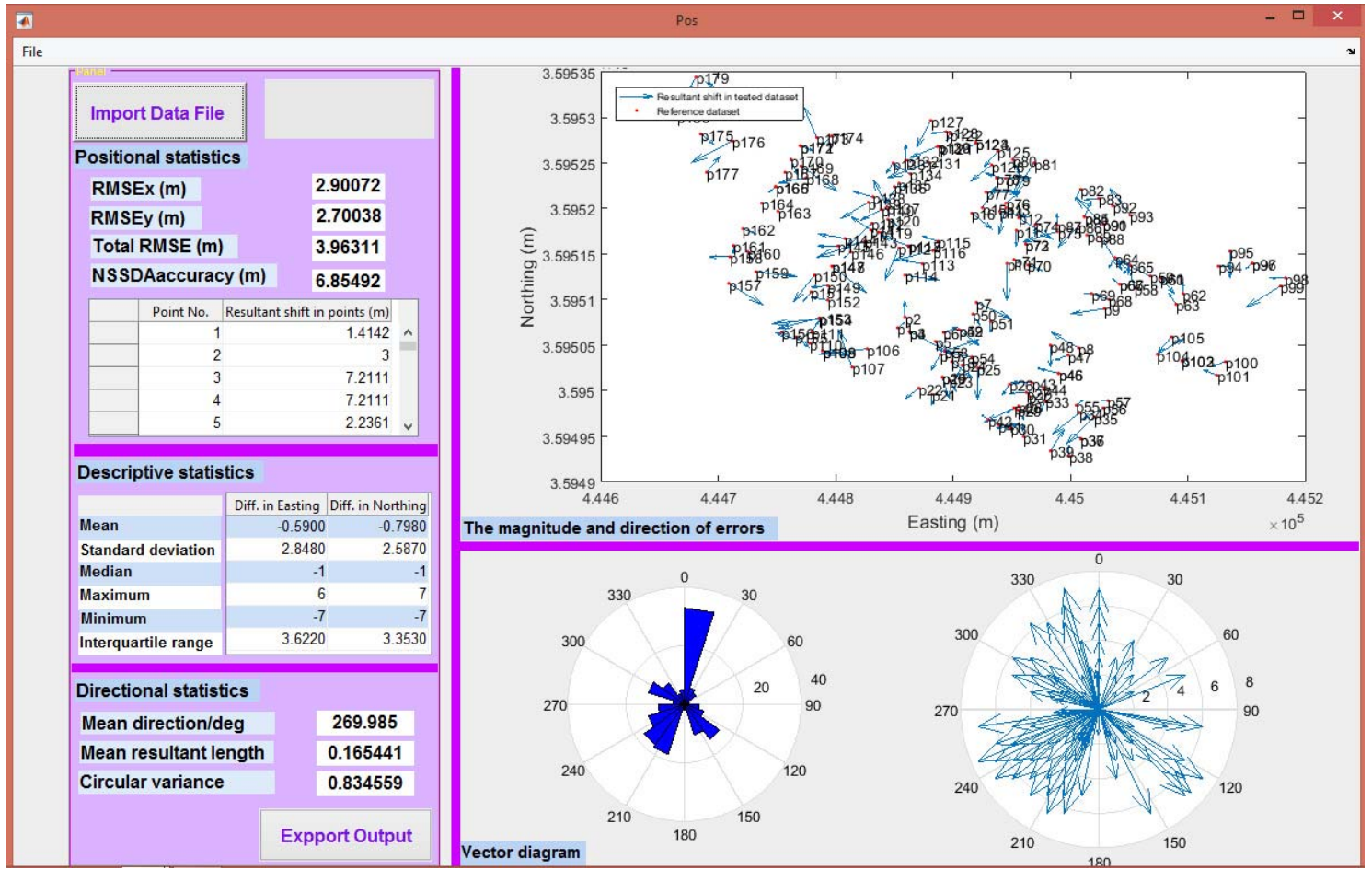

Figure 5. Calculation and visualization tool for RMSE (VGI points captured by GPS, compared to parcel coordinates from official mapping, Moharbeen urban area, Al-Hillah).

The calculated RMSE values were consistent for each data collection technology within a locality, but the summary statistics presented in Table 2 do indicate some variation. GPS accuracies suffered in urban areas due to limited satellite visibility and lack of stability for hand-held mobile devices. The iPad, with official base maps and QGIS functionality, appeared to be promising in terms of accuracy, although the rural communities could not be persuaded to use this technology: the majority preferred to annotate an analogue paper copy of the orthophoto, but misinterpretation (e.g., between shadows and land parcel edges) led to lower accuracies in some areas.

Table 2. Root mean square error (RMSE) for parcel corners for compared datasets aggregated by locality.

\begin{tabular}{ccccc}
\hline \multirow{2}{*}{ Study Area } & \multirow{2}{*}{$\begin{array}{c}\text { No. of Points } \\
\text { Tested }\end{array}$} & \multicolumn{3}{c}{ RMSE (Meters) cf. Official Data } \\
\cline { 3 - 5 } & & Smartphone GPS & iPad Tablet & Analogue Paper Photo \\
\hline Urban (4 sites) & 778 & 4.364 & 1.357 & 2.615 \\
Peri-urban (3 sites) & 308 & 2.933 & 1.354 & 2.190 \\
Rural (2 sites) & 139 & 3.23 & - & 3.41 \\
\hline
\end{tabular}

\subsection{Completeness Results from VGI}

Completeness was assessed by considering the total number of plots which are evident in the field, compared to those in the official records. A significant difference between the formal and volunteer totals has been found:

- Urban: 1235 plots on the official map; 2133 plots observed by the volunteers;

- Peri-Urban: 223 plots on the official map; 285 plots observed by the volunteers;

- Rural: 80 plots on the official map; 728 plots observed by the volunteers.

In the urban area there has been significant increase due to sub-division of plots. Occupying the same space, subdivided parcels are used for changes in land use, e.g., new shops; for developing 
new buildings within the parcel, e.g., additional houses; and for modified occupancy, e.g., new flats created from an original building. A typical example is of one land parcel, believed by the authorities to be a single plot, but identified by volunteers to have been sub-divided into three separate plots. Two of these were used for housing and the third consisted of several small shops, with a flat above. In another case, one owner of two individual large housing land plots had combined them to produce one plot, now containing five houses. Other locations highlighted a radical change of use, from purely residential to multiple use, including areas where all houses now have shops at the front. Peri-urban sites exhibit less change, because of lower land values (with less pressure to subdivide), and stable occupancy. In rural areas, some parts are very stable, but other locations have changed land use from agriculture to residential, and numerous housing plots have been created from one field. In one of the communities surveyed, a new irrigation scheme in an area where the official maps date from the 1950s, meant a completely different pattern and density of land parcels to that shown officially.

Table 3 shows the results of multiple crowdsourced VGI in testing the currency and validity of attribute data. Here, ownership details of sampled plots were to be determined: the official records of the name of a parcel's owner are incomplete and out-of-date, so each volunteer was asked for their opinion. In the vast majority of cases the 'crowd' of volunteers agreed on the name of the rightful owner: the percentage of disagreement in validating ownership data by consensus was low for each of the three different areas. It is concluded that ownership data obtained from groups of volunteers was correct, and could be used for validation and informing the official LAS organization.

Table 3. Verifying ownership data by crowdsource agreement.

\begin{tabular}{cccc}
\hline Study Area & $\begin{array}{c}\text { No. of Plots } \\
\text { Tested }\end{array}$ & $\begin{array}{c}\text { No. of Plots with Disagreement } \\
\text { Recorded in Naming the Owner }\end{array}$ & $\begin{array}{c}\text { Percentages of } \\
\text { Disagreement }\end{array}$ \\
\hline Urban (4 sites) & 200 & 9 & $5 \%$ \\
Peri-urban (3 sites) & 150 & 5 & $3 \%$ \\
Rural (2 sites) & 80 & 2 & $2 \%$ \\
\hline
\end{tabular}

\subsection{Experiences with Volunteers' Activity and Motivation}

In addition to analysis of the data collected in this VGI project, further factors related to the citizens involved were assessed during the fieldwork, including their preferences, opinions, and motivations. This was derived from interviews with volunteers, observation of the work being done in the field, and analysis of the data captured. Feedback sessions were held with volunteers after their participation, recording their opinions and taking the opportunity to report back to them on their work.

It is clear that citizen volunteers have valuable information on their communities which, if added to the formal land administration system, can help to update it. For example, in one of the case study sites, volunteers reported that the official map is too old, because a river shown on the map has dried up and the area of land is occupied by some residents. Another example relates to permissions: the out-of-date official map shows a block of land parcels which appear to be available for development but, in reality, the community now considers the area of that block to be a heritage area.

After using the three different methods of data collection to identify their own or others' plots, volunteers were asked to specify which was the easiest and why. In effect, the usability of, and preference for, high-tech methods (smartphone/GPS for picking up coordinates; iPad for digital boundary demarcation), or low-tech methods (ordinary pen to delineate plot boundaries on paper-printed satellite/aerial image, topographic map, sketch map) was determined (Table 4).

The urban area volunteers preferred the iPad tablet configuration, which was also the most accurate for them; but in the peri-urban areas the less cumbersome and less obtrusive smartphone option was preferred. Those in rural areas had a distinct antipathy to the tablet, with a slight preference for the analogue method. 
Table 4. Number of volunteer preferences for data collection methods in different communities.

\begin{tabular}{cccc}
\hline Areas & GPS Enabled Smart Phone & iPad Tablet & Analogue Paper Photo \\
\hline Urban & 10 & 17 & 14 \\
\hline Peri-urban & 17 & 7 & 13 \\
\hline Rural & 13 & 0 & 14 \\
\hline
\end{tabular}

At the end of the study, citizens, were asked about the reasons for their involvement. In Al-Hillah, as in many other areas of Iraq, and indeed other countries, the allocation, use, registration, occupancy, and transfer of land are extremely contentious issues and any formalised system of administration is open to all manner of professional incompetence, as well as fraud and profiteering. It was these issues which appeared to motivate the volunteers most strongly. Due to the localised ongoing unrest, long-term lack of resources, and basic inefficiency of the current system, several volunteers had direct experience, as land owners, of the land administration losing their documents inside their institute. Even when they are available, volunteers have been dissatisfied: a typical response was: "I visited the land registration system to change the category of my parcel. However, I was shocked when I saw that the file was full of dust and in a very bad condition; a few of the papers were lost... I was very depressed and angry at them for losing some documents in a place that we expected to be safe".

Volunteers were asked whether they were happy that they spent their time on the project and would they like to do more survey work (Table 5).

Table 5. Volunteer willingness to participate further.

\begin{tabular}{cccc}
\hline Study Area & Yes & No & Not Sure \\
\hline Urban (4 sites) & 35 & 3 & 3 \\
Peri-urban (3 sites) & 31 & 2 & 4 \\
Rural (2 sites) & 26 & 0 & 1 \\
Total & 92 & 5 & 8 \\
\hline
\end{tabular}

The majority answered that they would happy to be volunteers in the future for such projects. Reasons given for refusing, in contrast, were mainly related to the uncertain safety situation of the country and the threat of sectarian violence, along with a perception that data collection such as this was devious and an indirect means of government 'spying'. The recent years of conflict in civil society in Iraq, and its impact on societal structures, including the sense of community (which would promote volunteer activity such as this), does have an effect on projects such as the one described in this paper.

Further, some felt that their data collection work was challenging the official 'professionals', who had the sole responsibility and expertise to manage the LAS. One suggested that availability of VGI data "may encourage some dishonest people to deceive our data for forgery purposes, which is currently common in Iraq".

This section has discussed the field exercises undertaken during this research project. The data collected, both positional and attribute, have been analysed in terms of its accuracy, and its utility in enhancing official records. Further, the effect of different types of environment (urban, peri-urban, rural) has been investigated, as has the impact of differing cohorts of volunteers. Varying technologies have been applied. The impact and utility of the VGI collected in stressed societal circumstances has been presented, along with an investigation of the social and community aspects of this VGI exercise. The final part of this paper concludes with comments on the significance of the study.

\section{Discussion and Conclusions}

This project relied overwhelmingly on the willingness of communities to engage with VGI collection and to consider the value of VGI when used within those communities. The identification of 
'gatekeepers', representative and authoritative community leaders, was a major factor in successfully carrying out this project.

It was clear from initial interviews with the gatekeepers and with professional stakeholders, that the local municipality does not have the capacity to update or maintain the official land administration system. There had been a long-standing recognition of this situation, and an earlier attempt to sub-contract improvements to external consultants failed in 2006.

The potential for VGI within this system is, therefore, worthy of investigation. Analysis has shown the relative accuracy of different data collection methods in different contexts. It is argued here that, in some cases, it may be more important to collect some interim data, which the community can agree on and take ownership of, even if that means using a slightly less accurate method, than to focus simply on spatial accuracy. It can be concluded that in areas of conflict, or when official systems are under extreme stress, VGI may be the only realistic method of collecting usable data. In these cases, it may be more important to allow volunteers to choose a lower-accuracy method of data capture suited to their preferences and abilities.

Further conclusions relate to the advantages of incorporating VGI into the official land administration system.

1. Speed of data capture: the volunteer groups were able to gather more timely information within a few days than the hard-pressed official agency;

2. Lower costs: the use of basic technologies, including paper images and citizen-sourced annotation, has been shown to be sufficiently accurate for updating records in the official system. Even the more expensive methods, including GPS-enabled mobile phones and hand-held tablets, many already owned by volunteers, are cheaper than investing in agency-wide technologies relying on high-precision GPS or drone mapping programmes;

3. Updated registers of legally-acceptable standards: the speed and low cost of any VGI project of this type will result in significant amounts of valuable, contemporary information. This advantage is more contentious, as the definitive legal status of the VGI has not yet been formally confirmed (although the official agency has been encouraging), and it is also recognised that a more systematic approach to data collection will need to be developed, authorised, and monitored by the formal governmental body; and

4. Engagement of the community: encouraging the citizens and local stakeholders to 'take ownership' of the land registration process has significant societal benefits, and the community representatives (gatekeepers) were enthusiastic proponents of this research.

This paper has exemplified some of the issues involved in capturing VGI in circumstances where official law and order is limited and communities are not functioning in an ideal manner. Thus, in addition to the merits of using VGI, potential problems in enhancing or supplementing the land administration system with citizen-sourced VGI are recognized.

1. Embarking on a programme of data capture which relies on recruiting technically-aware and knowledgeable people, representative of a community, can be difficult: the gatekeepers were relied upon to find a willing cross-section of the local residents and business owners. Problems were encountered, for example, in encouraging female volunteers to use 'advanced' technologies. Technical skills in handling technology, training in filling out forms and recording the data required, and conflict resolution in small groups, all needed attention for successful VGI to be compiled;

2. Further, social problems were evident in contributors volunteering some of the information requested: questions such as 'who owns this land parcel?', 'is this land occupied illegally?', and 'how many people form the household in this property?' often proved uncomfortable for volunteers to ask;

3. There was also a perception, which was difficult to overcome, that this research was government-initiated, and the hostility of citizens to authority took much effort to overcome; 
4. The final merging of captured VGI with the official data: in terms of required accuracy, this would not be problematic, but the legal standing of information captured by citizens, as opposed to official agencies, has not yet been tested.

This paper has concentrated on considering different methods of data collection that can suit different types of people, in varying geographical contexts. The research has given opportunity for a representative sample of citizens to volunteer and participate, with varying levels of education and experience. The promising levels of accuracy and completeness of the VGI data and their possible inclusion in a fit-for-purpose LAS, are of significant interest to the authorities of Al-Hillah. It has been shown that, despite challenging circumstances in engaging with citizens and acquiring good-quality data, there is potential for incorporating VGI into the land administration system of a poorly-documented, yet dynamic, area of a country which faces many problems.

Acknowledgments: The authors would like to thankfully acknowledge the contribution of the volunteers of Al-Hillah, the officials at the Land Administration Office in the municipality, Babylon University, and the Iraqi Cultural Attaché (London) for financial support.

Author Contributions: S.S.'s experience in urban environments in developing countries set the context for this study; D.F. directed the research programme and the writing of this paper; M.H. developed the methodology for the data collection exercise and conducted all the fieldwork in Iraq.

Conflicts of Interest: The authors declare no conflict of interest.

\section{References}

1. Goodchild, M. Citizens as sensors: The world of volunteered geography. GeoJournal 2007, 69, 211-221. [CrossRef]

2. Goodchild, M. Commentary: Whither VGI? GeoJournal 2008, 72, 239-244. [CrossRef]

3. US Agency for International Development (USAID), Iraqi Local Governance Program. Land Registration and Property Rights in Iraq; C. N: EDG-C-00-03-00010-00; RTI International: Baghdad, Iraq, 2005.

4. McLaren, R. Engaging the Land Sector Gatekeepers in Crowdsourced Land Administration. In Proceedings of the World Bank Land and Poverty Conference, Washington, DC, USA, 8-11 April 2013.

5. Enemark, S.; Bell, K.; Lemmen, C.; McLaren, R. Fit-for-Purpose Land Administration. In FIG Publication No 60; Enemark, S., Ed.; International Federation of Surveyors (FIG): Rome, Italy; World Bank: Copenhagen, Denmark, 2014; ISBN 978-87-9-285311-0.

6. Keenja, E.; De Vries, W.; Bennett, R.; Laarakker, P. Crowd sourcing for land administration: Perceptions within Netherlands Kadaster. In FIG Working Week 2012: Knowing to Manage the Territory, Protect the Environment, Evaluate the Cultural Heritage, Rome, Italy, 6-10 May 2012; International Federation of Surveyors (FIG): Rome, Italy, 2012.

7. Basiouka, S.; Potsiou, C.; Bakogiannis, E. OpenStreetMap for cadastral purposes: An application using VGI for official processes in urban areas. Surv. Rev. 2015, 47, 333-341. [CrossRef]

8. Grus, M.; Hogerwerf, J. VGI and Map Production in The Netherlands' Kadaster. In Proceedings of the VGI Workshop, Paris, France, 28 March 2014.

9. De Almeida, J.-P.; Haklay, M.; Ellul, C.; Carvalho, M. The role of Volunteered Geographic Information towards 3D Property Cadastral Systems. In Proceedings of the 4th International Workshop on 3D Cadastres, Dubai, UAE, 9-11 November 2014.

10. Niederer, S.; van Dijck, J. Wisdom of the Crowd or Technicity of Content? Wikipedia as a socio-technical system. New Media Soc. 2010, 12, 1368-1387. [CrossRef]

11. Bonney, R.; Cooper, C.; Dickinson, J.; Kelling, S.; Phillips, T.; Rosenberg, K.; Shirk, J. Citizen science: A developing tool for expanding science knowledge and scientific literacy. BioScience 2009, 59, 977-984. [CrossRef]

12. De Vries, W.; Bennett, R.; Zevenbergen, J. Neo-cadastres: Innovative solution for land users without state based land rights, or just reflections of institutional isomorphism? Surv. Rev. 2014, 47, 220-229. [CrossRef]

13. Seeger, $\mathrm{C}$. The role of facilitated volunteered geographic information in the landscape planning and site design process. Geojournal 2008, 72, 199-213. [CrossRef] 
14. Coleman, D. Volunteered geographic information in spatial data infrastructure: An early look at opportunities and constraints. In Proceedings of the 12th GSDI Association World Conference, Singapore, 19-22 October 2010.

15. Brown, G.; Kelly, M.; Whitall, D. Which 'public'? Sampling effects in public participation GIS (PPGIS) and volunteered geographic information (VGI) systems for public lands management. J. Environ. Plan. Manag. 2014, 57, 190-214. [CrossRef]

16. Basiouka, S.; Potsiou, C. VGI in Cadastre: A Greek experiment to investigate the potential of crowd sourcing techniques in Cadastral Mapping. Surv. Rev. 2012, 44, 153-161. [CrossRef]

17. Cotfas, L.; Diosteanu, A. Evaluating Accessibility in Crowdsourcing GIS. J. Appl. Collab. Syst. 2010, 2, 45-49.

18. Tulloch, D. Many, many maps: Empowerment and online participatory mapping. First Monday 2007, 12, 2. [CrossRef]

19. Haklay, M.; Antoniou, V.; Basiouka, S.; Soden, R.; Mooney, P. Crowdsourced Geographic Information Use in Government; World Bank GFDRR: London, UK, 2014; 76p.

20. Berdou, E. Mediating Voices and Communicating Realities. Using Information Crowd-Sourcing Tools, Open Data Initiatives and Digital Media to Support and Protect the Vulnerable and Marginalized; Institute of Development Studies: Brighton, UK, 2011.

21. Bégin, D. Towards Integrating VGI and National Mapping Agency Operations: A Canadian Case Study. In Proceedings of the Workshop on the Role of Volunteered Geographic Information in Advancing Science: Quality and Credibility, Columbus, OH, USA, 18 September 2012.

22. Brandeis, M.; Nyerges, T. Assessing Resistance to Volunteered Geographic Information Reporting within Local Government. Trans. GIS 2016, 20, 203-220. [CrossRef]

23. Ciepłuch, B.; Jacob, R.; Mooney, P.; Winstanley, A. Comparison of the accuracy of OpenStreetMap for Ireland with Google Maps and Bing Maps. In Proceedings of the Ninth International Symposium on Spatial Accuracy Assessment in Natural Resuorces and Enviromental Sciences, International Spatial Accuracy Research Association, Leicester, UK, 20-23 July 2010.

24. Devillers, R.; Jeansoulin, R. Spatial data quality: Concepts. In Fundamentals of Spatial Data Quality; Rodolphe, D., Robert, J., Eds.; Wiley-ISTE: London, UK, 2010; pp. 31-42.

25. Shi, W.; Fisher, P.; Goodchild, M. Spatial Data Quality; Taylor \& Francies: London, UK, 2003.

26. Veregin, H. Data quality parameters. In Geographical Information Systems, 2nd ed.; Longley, P., Goodchild, M., Maguire, D., Rhind, D., Eds.; John Wiley and Sons: New York, NY, USA, 1999; Chapter 12; Volume 1, pp. 177-189.

27. Hashemi, P.; Abbaspour, R. Assessment of Logical Consistency in OpenStreetMap Based on the Spatial Similarity Concept. In OpenStreetMap in GIScience; Lecture Notes in Geoinformation and Cartography; Arsanjani, J., Zipf, A., Mooney, P., Helbich, M., Eds.; Springer: Zug, Switzerland, 2015; pp. 19-36.

28. Fairbairn, D.; Al-Bakri, M. Using geometric properties to evaluate possible integration of authoritative and volunteered geographic information. ISPRS Int. J. Geo-Inf. 2013, 2, 349-370. [CrossRef]

29. Zielstra, D.; Zipf, A. A comparative study of proprietary geodata and volunteered geographic information for Germany. In Proceedings of the 13th AGILE International Conference on Geographic Information Science, Guimarães, Portugal, 11-14 May 2010.

30. Brassel, K.; Bucher, F.; Stephan, E.M.; Vckovski, A. Completeness. In Elements of Spatial Data Quality; Guptill, S., Morrison, J., Eds.; Elsevier: Oxford, UK, 1995; pp. 81-108.

31. Haklay, M. How good is volunteered geographical information? A comparative study of OpenStreetMap and Ordnance Survey datasets. Environ. Plan. B 2010, 37, 682-703. [CrossRef]

32. Jackson, S.; Mullen, W.; Agouris, P.; Crooks, A.; Croitoru, A.; Stefanidis, A. Assessing completeness and spatial error of features in volunteered geographic information. ISPRS Int. J. Geo-Inf. 2013, 2, 507-530. [CrossRef]

33. Adlington, G.; Tonchovska, R. Good Governance of Tenure. FAO and World Bank Support and Future Agendas. In Proceedings of the 4th Regional Conference for Cadastre and Spatial Data Infrastructure, Bled, Slovenia, 8-10 June 2010.

34. Lemmen, C. The Social Tenure Domain Model: A Pro-Poor Land Tool. In FIG Publication No 52; Uitermark, H., Lemmen, C., Eds.; International Federation of Surveyors (FIG): Copenhagen, Denmark, 2010; ISBN 978-87-9-090783-9. 
35. Alemie, K.; Bennett, R.; Zevenbergen, J. Evolving urban cadastres in Ethiopia: The impacts on urban land governance. Land Use Policy 2015, 42, 695-705. [CrossRef]

36. Al-Bakri, M.; Fairbairn, D. Assessing similarity matching for possible integration of feature classifications of geospatial data from official and informal sources. Int. J. Geogr. Inf. Sci. 2012, 26, 1437-1456. [CrossRef]

37. Lanier, J. Digital Maoism: The hazards of the new online collectivism. Edge 2011, 183, 30.

38. Keen, A. The Cult of the Amateur: How Blogs, MySpace, YouTube and the Rest of Today's User Generated Media Are Killing Our Culture; Doubleday: New York, NY, USA, 2011.

39. Goodchild, M.; Li, L. Assuring the quality of volunteered geographic information. Spat. Stat. 2012, 1, 110-120. [CrossRef]

40. Navratil, G.; Frank, A. VGI for land administration-A quality perspective. ISPRS-Int. Arch. Photogramm. Remote Sens. Spat. Inf. Sci. 2013, 1, 159-163. [CrossRef]

41. Bishr, M.; Mantelas, L. A trust and reputation model for filtering and classifying knowledge about urban growth. GeoJournal 2008, 72, 229-237. [CrossRef]

42. Haklay, M.; Basiouka, S.; Antoniou, V.; Ather, A. How many volunteers does it take to map an area well? Cartogr. J. 2010, 47, 315-322. [CrossRef]

43. Maué, P. Reputation as tool to ensure validity of VGI. In Proceedings of the Workshop on Volunteered Geographic Information, Santa Barbara, CA, USA, 13-14 December 2007.

44. Forrester, J.; Cinderby, S. Guide to Using Community Mapping and Participatory GIS; NERC: Swindon, UK, 2014.

(C) 2017 by the authors. Licensee MDPI, Basel, Switzerland. This article is an open access article distributed under the terms and conditions of the Creative Commons Attribution (CC BY) license (http://creativecommons.org/licenses/by/4.0/). 